\title{
REVIEW
}

\section{Childhood leukaemia in the vicinity of German nuclear power plants - some missing links}

Friedo Zölzer

Department of Radiology and Toxicology, Faculty of Health and Social Studies, University of South Bohemia, České Budějovice, Czech Republic

Received $10^{\text {th }}$ December 2009.

Revised $20^{\text {th }}$ January 2010.

Published online $25^{\text {th }}$ January 2010.

\begin{abstract}
Summary
A recent epidemiological study in Germany, the so-called KiKK study, came to the conclusion that there was a relationship between a child's risk of contracting leukaemia in the first 5 years of life and the distance of its residence from the nearest nuclear power plant. The risk of children inside a $5 \mathrm{~km}$ radius was found to be 2.19 times that of children outside, with a lower $95 \%$ confidence limit of 1.51 . The study seems to be epidemiologically sound and solid, and its results agree with earlier evidence about childhood leukaemia in the vicinity of nuclear installations. It does not show, however, nor does it at all claim to show, that the phenomenon was due to radiation exposure. The measured doses in the area around German nuclear power plants are at least a factor 1000 smaller than what would be needed to explain the number of leukaemia cases observed. Additional evidence suggests that the main effect was a shift of the age distribution towards younger ages, with the overall incidence for all age groups not affected, which would be rather unexpected as a radiation effect. Still other studies have shown that elevated risks can even be observed around so-called "planning sites", where no nuclear facility has ever been built. It thus seems justified to speak of "missing links" between the elevated risk of childhood leukaemia around nuclear power plants on the one hand, and the radiation exposure caused by their normal operation on the other.
\end{abstract}

Key words: KiKK; radiation; risk; leukaemia; health

\section{INTRODUCTION}

In December 2007, the German Federal Office for Radiation Protection (Bundesamt für Strahlenschutz) presented to the public "An Epidemiological Study of Childhood Leukaemia in the vicinity of Nuclear Power Plants" ("Epidemiologische Studie zu

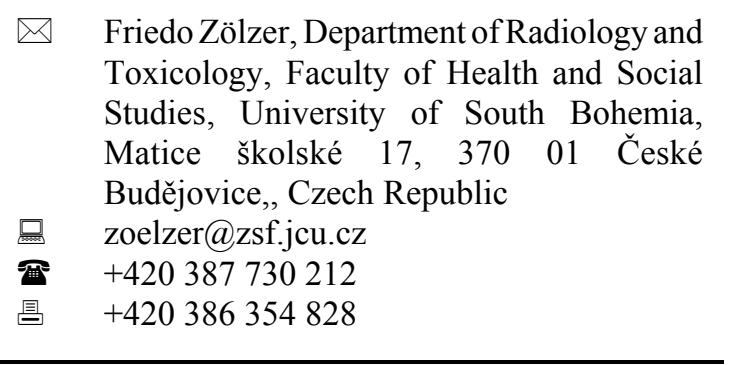

Kinderkrebs in der Umgebung von Kernkraftwerken”, in the German public often referred to as "KiKK-Studie"; Kaatsch et al. 2007). The main results were published in English shortly afterwards (Kaatsch et al. 2008, Spix et al. 2008). This study aroused extraordinary public interest, because it showed a relationship between a child's risk of contracting leukaemia in the first 5 years of life and the distance of its residence from the nearest nuclear power plant. Although the study summary cautioned against hasty conclusions, emphasizing that "no statement can be made about the biological risk factors that might explain this relationship", the findings seemed to imply that radioactivity released from or radiation emitted by the nuclear plants must be the cause of the increased leukaemia risk. There was an uproar in the media, press releases from supporters and opponents of nuclear energy, 
statements of real and self-styled experts, and finally a request by the Federal Ministry of the Environment to its Radiation Protection Commission (Strahlenschutzkommission) for an independent review of the study. The final report of this review was released in October 2008. It serves as the main, but not the only basis of the following commentary.

\section{SOME GENERAL FACTS ABOUT CHILDHOOD LEUKAEMIA}

Leukaemia is a cancer of the blood-forming tissues and is characterized by an abnormal proliferation of white blood cells (leukocytes). The most frequently occurring morphological types are acute lymphoblastic leukaemia and acute myeloblastic leukaemia (ALL and AML) much less frequent are their chronic counterparts (CLL and CML). Leukaemias account for about a third of all childhood cancers, the proportion decreasing with age (Lightfoot and Roman 2004). More than $80 \%$ of all cases are ALL and about 15\% AML, which leaves less than 5\% for the other types (Kaatsch and Mergenthaler 2008). The age distribution shows a maximum around 2-3 years for lymphoblastic leukaemia and around 1 year for myeloblastic leukaemia. In Europe, leukaemia occurs with an incidence rate of 4-5 per 100000 children. This incidence rate has been increasing by about half a percent per year over the last few decades (Kaatsch and Mergenthaler 2008).

There are also considerable geographical variations. In Germany, for instance, some counties (Landkreise) have an incidence rate of less than half the average, while in others the incidence rate is more than double the average (Kaatsch and Mergenthaler 2008). Although many factors have been identified which play a role in the aetiology of childhood leukaemia, such as genetic predisposition, nutrition, allergies, and environmental factors, it is not clear how exactly they influence incidence rates or their temporal and spatial variations (Lightfoot and Roman 2004). One particular fact is that rural areas tend to have a higher than average incidence, which may be related to population mixing as discussed below.

\section{THE MAIN FINDINGS OF THE SO-CALLED KIKK STUDY}

The latest study of childhood leukaemia around German nuclear power plants was designed to test the hypothesis that children living close to these installations have an increased risk of contracting leukaemia before their $5^{\text {th }}$ birthday. The distance from the nuclear power plant was supposed to serve as a proxy for the radiation exposure of the children; no attempt was made to actually measure radiation doses.

The authors of the study chose a case-control design, analyzing data for all 1592 children in the study regions who were diagnosed with cancer of any type between 1980 and 2003. These cases were matched with 4735 controls, i.e. children of the same age, sex and year of residence in the study region. Each study region was defined as the county in which one of the 16 German nuclear power plants was situated, the closest neighbouring county and the closest county to the east. The study period began in the year after the start of the power plant's operation, and ended 5 years after its decommissioning. Although all types of cancer were included in the study, only the results for leukaemia are discussed here, because none of the other types yielded any significant results.

For leukaemia, 593 cases were matched with 1766 controls. The statistical evaluation of the data showed a significant trend towards a higher leukaemia risk for children living closer to a nuclear power plant. When the Odds Ratio (which for small probabilities are the same as the Relative Risk) was described as $\mathrm{OR}=1+\beta / \mathrm{x}$, where $\mathrm{x}$ is the distance in $\mathrm{km}$ from the next power plant, the factor $\beta$ came out as $1.75 \mathrm{~km}$, with a lower $95 \%$ confidence limit of $0.46 \mathrm{~km}$. For instance, a child living at a distance of $3.5 \mathrm{~km}$ would have a Relative Risk of 1.5 (50\% above normal), whereas a child living at $17.5 \mathrm{~km}$ would have a Relative Risk of just 1.1 ( $10 \%$ above normal). When the data were evaluated not continuously (as a trend with the distance from the power plant), but in two categories (either closer to or further away from the power plant than a certain distance), it was found that the risk of children inside the $5 \mathrm{~km}$ radius was 2.19 times that of children outside, with a lower $95 \%$ confidence limit of 1.51 .

It should be noted that the absolute number of cases was comparatively small. There were altogether 37 cases of leukaemia within the $5 \mathrm{~km}$ radius, where statistically 17 cases would have been expected. The 20 additional cases occurred over a period of 23 years, which means less than 1 additional case per year. That, of course, is no comfort to the affected children and their families, but it shows how extremely thin the statistical basis of the study is. Nevertheless, the review of the Radiation Protection Commission states that the statistical methods used were adequate and "according to good epidemiological practice". Some details are criticized, but the main findings are confirmed. 


\section{COMPARISON WITH OTHER STUDIES}

This study was not the first to analyse data of children living close to nuclear installations. An excess of childhood leukaemia was first observed in the vicinity of the fuel reprocessing plant Sellafield near Seascale in West Cumbria, England (COMARE 1986). Later, similar findings were reported around the Dounreay Nuclear Establishment in Scotland (COMARE 1988) and around the fuel reprocessing plant at La Hague in France (Guizard et al. 2001), to name just two further examples. A leukaemia cluster was also found to exist in the community of Elbmarsch in northern Germany, within a distance of $5 \mathrm{~km}$ from the Krümmel nuclear power plant (Schmitz-Feuerhake et al. 1993). In this latter case, 9 cases of childhood leukaemia were observed between 1990 and 1996, which is a more than threefold increase over the expected number (Laurier et al. 2002).

When epidemiological studies were carried out including all nuclear power plants in Germany, partly contradictory conclusions were reached. A paper in 1992, by authors from the same institution as the KiKK study, claimed that there was an increased relative risk of acute leukaemia before five years of age for children living within a $5 \mathrm{~km}$ radius around German nuclear installations. This seemed to be mainly due, however, to an unusually low incidence in the control regions chosen for the study (Michaelis et al. 1992). A later report in 1998 did not confirm the earlier findings, although it said that the relative risk for the children in question was 1.39 , but this figure was not significantly different from 1.00 (Kaatsch et al. 1998). The fact is that the KiKK study, which shared two thirds of its data with its predecessor, now produced a much clearer result $(\mathrm{RR}=2.19)$, which can probably be attributed to its case-control design. It may be interesting to note that exclusion of the cases from the cluster around the Krümmel nuclear power plant would not have changed the overall result of the KiKK study dramatically $(\mathrm{RR}=1.96$, Kaatsch et al. 2008).

A recent meta-analysis of 17 studies from 8 countries (Baker and Hoel 2007) looked at data for children of different age groups living in the proximity of nuclear facilities, where "proximity" in some cases meant "closer than $10 \mathrm{~km}$ ", in other cases "in the same county". These reports were greatly at variance with each other, some showing increased risks, some reduced risks, but significance was hardly ever reached. Nevertheless, pooling the data in the meta-analysis gave a clear result, namely that standardized incidence ratios were between 1.07 and 1.25 for children living near nuclear facilities, with confidence intervals not containing 1.00 for most age groups and geographic zones. It should be mentioned that the meta-analysis was based on a selection of 17 out of 37 individual studies and that the selection criteria have been criticised (Spix and Blettner 2009). It is unclear, however, if that really created an undue bias.

While most studies in the past did not pay special attention to the age group below 5 and a distance less than $5 \mathrm{~km}$, two recent studies from France and Great Britain were designed to match the German study as closely as possible. The French study showed a standard incidence ratio for the children in question of 0.96 , but that was based on the difference between 5 observed cases and 5.2 expected (Laurier et al. 2008). The British study reported 18 observed cases against 14.6 expected, which looked like an increase, but did not reach significance either (Bithell et al. 2008). For the time being, the KiKK study remains the largest and statistically strongest of such analyses, and it seems reasonable to accept, for now, that there is indeed an elevated risk for childhood leukaemia in the vicinity of nuclear power plants.

\section{THE POSSIBLE RADIATION DOSES INVOLVED}

As to the possible reasons for such an excess of leukaemia cases, the authors of the study said that "no statement can be made about the possible biological risk factors which may explain this relationship". This was due to the fact that the radiation doses to which children living close to the German nuclear power plants could have been exposed, to the best of everybody's knowledge, were far too small to explain the observed increase in risk.

The 2008 review by the German Radiation Protection Commission also addressed this point. It stated that releases of radioactivity from German nuclear power plants are monitored by a combined system of emission and immission control, which ensures the detection of external and internal exposures to radiation in the vicinity of the installations. The review specifically states that "the experience with the atmospheric nuclear weapons tests and with the Chernobyl accident leads to the conclusion that an additional radioactivity causing radiation exposures to more than $0.01 \mathrm{mSv}$ annually would leave such distinct traces in the environment that they could be reliably measured". The stated dose of $0.01 \mathrm{mSv}$ is more than 200 times smaller than the annual background exposure in Germany. The real radiation exposure of people living close to the nuclear power plants, of course, most probably 
differed from the natural background exposure by even less than the detectable $0.01 \mathrm{mSv}$ annually.

The review continues to say that a relative risk of 2.19 for leukaemia, as was found for children under the age of 5 living within a $5 \mathrm{~km}$ radius around nuclear power plants, would be indicative of an exposure to at least $10 \mathrm{mSv}$ in utero. This estimate is based on the results of the Oxford Survey of Childhood Cancers and similar studies, which looked at the leukaemia risk of children exposed to diagnostic X-rays mainly during the third trimester of pregnancy. These studies pointed to an excess relative risk of about 50 per $\mathrm{Sv}$, which is more than 10 times that of adults (Wakeford 2008). A comparison with the risk from in utero exposure is clearly the most appropriate here, because leukaemia is induced by radiation with a latency period of a few years and thus a major proportion of the cases appearing before the $5^{\text {th }}$ birthday would be induced during pregnancy. A dose of $10 \mathrm{mSv}$, however, is more than 1000 times higher than what could reliably have been detected by the monitoring system around the German nuclear power plants.

\section{THE QUESTION OF AGE}

In the meta-analysis of Baker and Hoel (2007), standardized incidence ratios were always higher for children under the age of 9 than for children and youth under the age of 25 . This is an interesting fact not addressed in the German study of 2007, which was limited to children under the age of 5 . However, one of the earlier German reports mentioned above (Kaatsch et al. 1998), which also pointed towards an increased risk for these younger children, even though the results were not statistically significant, found no evidence of an increase when all children under the age of 15 living within a $15 \mathrm{~km}$ radius around nuclear power plants were included. Similarly, a re-analysis of data from Great Britain (COMARE 2005) did not show a general excess of leukaemia cases around nuclear installations, but a higher risk for children under the age of 5 than for those between the ages of 5 and 14.

All this supports the notion that the children's age is of critical importance in this context. It has even been proposed (Grosche 2008) that what we are dealing with here is not a general increase in the incidence rate for leukaemia, but rather a shift in the age distribution towards younger ages, where the higher risk for children under 5 would be compensated by a lower risk for children between 5 and 14.
Such a shift, however, would be rather unexpected as a radiation effect. The data from the survivors of Hiroshima and Nagasaki, for instance, do not suggest an elevated incidence in some age groups which is compensated by a reduction in others, although admittedly few of the survivors were exposed in utero and no firm conclusion can be drawn for the age groups of primary interest here (Preston et al. 1994). Also, the exposures from the atomic bomb explosions were acute, while those around nuclear power plants, if they occurred, would presumably be protracted, so that the two cases are not fully comparable. Further investigation is clearly needed in this area.

\section{OTHER POSSIBLE EXPLANATIONS}

Perhaps the most surprising facts in this whole context relate to the question of leukaemias around so-called "planning sites", which unfortunately is not addressed at all in the study discussed here and is only mentioned in passing in the later review by the Radiation Protection Commission. Excess mortality was observed in regions which had once been considered for the building of a nuclear facility, but in which nothing of the kind was ever built (Cook-Mozaffari et al. 1989, Michaelis et al. 1992). Similarly, when incidence rates were compared before and after the start-up of a facility, they remained unchanged; where incidence rates were elevated, they had been already elevated before any radiation was ever produced (Baron 1984, further quotes in Baker and Hoel 2007).

What the explanation of such increased incidence without radiation is, nobody seems to know. One hypothesis, or rather speculation, suggests that leukaemia can be caused by an as yet unknown infectious agent, which is shared between different people when population mixing occurs (Kinlen 1988). The influx of new workers and their families into the rural areas in which nuclear installations are built could create such a situation. That population mixing is indeed associated with an elevated incidence of childhood leukaemia, has been shown in a number of studies (Kinlen et al. 1995, further quotes in Boutou et al. 2002). The effect seems to at least in part explain the above mentioned observations around the reprocessing plants Sellafield (Dickinson and Parker 1999) and La Hague (Boutou et al. 2002). The most important draw-back of the population mixing hypothesis, however, is that the infectious agent which presumably causes all those leukaemias more than 20 years after the creation of the hypothesis has not yet been identified. 
There is another problem with the population mixing hypothesis: it cannot easily account for the observations around "planning sites", as the influx of new people would probably not have started there. Rural areas in general, even those with low population mixing, tend to have an increased incidence rate, but the increase is less dramatic (Alexander et al. 1990, Boutou et al. 2002). The KiKK study, although not addressing the question of "planning sites", suggests that other factors must play a role. A re-evaluation of its data for the review of the Radiation Protection Commission showed that the leukaemia risk for children under the age of five living inside the $5 \mathrm{~km}$ radius was significantly increased both in rural and in mixed or urban areas. It is therefore probably better to say that we simply do not know what is happening.

\section{CONCLUSION}

In summary, we can state that the 2007 study initiated by the German Federal Office for Radiation Protection is epidemiologically sound and solid, and gives clear evidence that children under the age of 5 have an increased incidence of leukaemia if they live within a $5 \mathrm{~km}$ radius around a nuclear power plant. The absolute number of additional cases is in the order of 1 per year for the whole of Germany, although the relative risk is more than 2 .

A number of observations, however, would seem to make it highly improbable that this phenomenon is due to radiation exposure. The measured doses in the area are far too small, the shift in age distribution is rather unexpected as a radiation effect, and similarly elevated risks can be observed around so-called "planning sites". Obviously, there are some "missing links" between childhood leukaemia around nuclear power plants and the radiation exposure caused by their normal operation.

The option of nuclear energy may have to be rejected on other grounds, such as the remaining risk of a core meltdown or the unresolved problems of permanent waste disposal, but with any such problem we have to seek the best evidence available instead of proceeding from preconceived ideas. And our best evidence currently suggests that the operation of nuclear power plants in itself does not pose a threat to human health - whatever may be going on in the regions where they tend to be built.

\section{REFERENCES}

Alexander FE, Ricketts TJ, McKinney PA, Cartwright RA: Community lifestyle characteristics and risk of acute lymphoblastic leukaemia in children. Lancet 336:1461-1465, 1990.

Baker PJ, Hoel DG: Meta-analysis of standardized incidence and mortality rates of childhood leukaemia in proximity to nuclear facilities. Eur J Cancer Care (Engl) 16:355-363, 2007.

Baron JA: Cancer mortality in small areas around nuclear facilities in England and Wales. $\mathrm{Br} \mathrm{J}$ Cancer 50:815-824, 1984.

Bithell JF, Keegan TJ, Kroll ME, Murphy MF, Vincent TJ: Childhood leukaemia near British nuclear installations: methodological issues and recent results. Radiat Prot Dosimetry 132:191-197, 2008.

Boutou O, Guizard AV, Slama R, Pottier D, Spira A: Population mixing and leukaemia in young people around the La Hague nuclear waste reprocessing plant. Br J Cancer 87:740-745, 2002.

Committee on Medical Aspects of Radiation in the Environment (COMARE): First Report. The implications of the new data on the releases from Sellafield in the 1950s for the conclusions of the Report on the Investigation of the Possible Increased Incidence of Cancer in West Cumbria. HMSO, London 1986.

Committee on Medical Aspects of Radiation in the Environment (COMARE): Second Report. Investigation of the possible increased incidence of leukaemia in young people near the Dounreay Nuclear Establishment, Caithness, Scotland. HMSO, London 1988.

Committee on Medical Aspects of Radiation in the Environment (COMARE): Tenth Report. The incidence of childhood cancer around nuclear installations in Great Britain. Health Protection Agency, London 2005.

Cook-Mozaffari P, Darby S, Doll R: Cancer near potential sites of nuclear installations. Lancet 11:1145-1147, 1989.

Dickinson HO, Parker L: Quantifying the effect of population mixing on childhood leukaemia risk: the Seascale cluster. Br J Cancer 81:144-151, 1999.

Grosche B: The risk of childhood leukaemia in the vicinity of nuclear installations: A review. Radioprotection 43:60-61, 2008.

Guizard AV, Boutou O, Pottier D, Troussard X, Pheby D, Launoy G, Slama R, Spira A: The incidence of childhood leukaemia around the La Hague nuclear waste reprocessing plant (France): 
A survey for the years 1978-1998. J Epidemiol Community Health 55:469-474, 2001.

Kaatsch P, Mergenthaler A: Incidence, time trends and regional variation of childhood leukaemia in Germany and Europe. Radiat Prot Dosimetry 132:107-113, 2008.

Kaatsch P, Kaletsch U, Meinert R, Michaelis J: An extended study on childhood malignancies in the vicinity of German nuclear power plants. Cancer Causes Control 9:529-533, 1998.

Kaatsch P, Spix C, Schmiedel S, Schulze-Rath R, Mergenthaler A, Blettner M: Epidemiologische Studie zu Kinderkrebs in der Umgebung von Kernkraftwerken, Bundesamt für Strahlenschutz, Salzgitter, 2007 (available on-line at http://www.bfs.de/de/bfs/druck/Ufoplan/4334 KiKK_Gesamt T.pdf).

Kaatsch P, Spix C, Schulze-Rath R, Schmiedel S, Blettner M: Leukaemia in young children living in the vicinity of German nuclear power plants. Int J Cancer 15:721-726, 2008.

Kinlen L: Evidence for an infective cause of childhood leukaemia: Comparison of a Scottish new town with nuclear reprocessing sites in Britain. Lancet 10:1323-1327, 1988.

Kinlen LJ, Dickson M, Stiller CA: Childhood leukaemia and non-Hodgkin's lymphoma near large rural construction sites, with a comparison with Sellafield nuclear site. Brit Med J 310:763-768, 1995.

Laurier D, Grosche B, Hall P: Risk of childhood leukaemia in the vicinity of nuclear installations-findings and recent controversies. Acta Oncol 41:14-24, 2002.

Laurier D, Jacob S, Bernier MO, Leuraud K, Metz C, Samson E, Laloi P: Epidemiological studies of leukaemia in children and young adults around nuclear facilities: A critical review. Radiat Prot Dosimetry 132:182-190, 2008.
Lightfoot TJ, Roman E: Causes of childhood leukaemia and lymphoma. Toxicol Appl Pharmacol 199:104-117, 2004.

Michaelis J, Keller B, Haaf G, Kaatsch P: Incidence of childhood malignancies in the vicinity of west German nuclear power plants. Cancer Causes Control 3:255-263, 1992.

Preston DL, Kusumi S, Tomonaga M, Izumi S, Ron E, Kuramoto A, Kamada N, Dohy H, Matsuo T, Nonaka H, Thompson DE, Soda M, Mabuchi K: Cancer incidence in atomic bomb survivors. Part III: Leukemia, lymphoma and multiple myeloma, 1950-1987. Radiat Res 137S:68-97, 1994.

Schmitz-Feuerhake I, Schröder H, Dannheim B, Grell-Büchtmann I, Heimers A, Hoffmann W, Nahrmann A, Tomalik P: Leukaemia near water nuclear reactor. Lancet 342:1484, 1993.

Spix C, Blettner M: Re: Baker PJ \& Hoel DG (2007) European Journal of Cancer Care 16, 355-363. Meta-analysis of standardized incidence and mortality rates of childhood leukaemia in proximity to nuclear facilities. Eur J Cancer Care (Engl) 18:429-430, 2009.

Spix C, Schmiedel S, Kaatsch P, Schulze-Rath R, Blettner M: Case-control study on childhood cancer in the vicinity of nuclear power plants in Germany 1980-2003. Eur J Cancer 44:275-284, 2008.

Strahlenschutzkommission: Bewertung der epidemiologischen Studie zu Kinderkrebs in der Umgebung von Kernkraftwerken (KiKK-Studie). Berichte der Strahlenschutzkommission (SSK), Heft 57, 2008 (available on-line at http://www.ssk.de/de/werke/2008/volltext/ssk08 15.pdf).

Wakeford R: Childhood leukaemia following medical diagnostic exposure to ionizing radiation in utero or after birth. Radiat Prot Dosimetry 132:166-174, 2008. 